\title{
Appreciation
}

\section{Professor Bryan Fredrick Warren - a true friend of pathology in Sri Lanka}

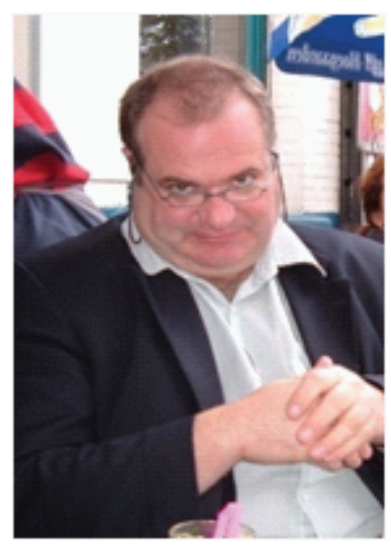

Professor Bryan Fredrick Warren passed away on 28th March 2012 at a dismayingly young age of 53 years, after bravely battling intestinal cancer for five long years, a complication of Crohns disease, which he developed during childhood, a disease on which he was one of the worlds leading experts. Bryan Warren was no stranger to our land and was much loved by Sri Lankan Gastroenterologists and Pathologists alike. I therefore, will set down on paper more of the human side of this great man rather than his academic prowess.

The first time he set foot on the shores of Sri Lanka was in April 1996 to deliver a guest lecture on "Iatrogenic Gastrointestinal Disease" at the Asia Pacific Gastrointestinal Meeting. After the lecture one of my colleagues was heard to comment " I generally go to sleep during pathology lectures - but this lecture was delivered straight from the gut". Bryan in turn fell in love with Sri Lankan cuisine, especially hoppers of which he was inordinately fond, being rumored to have knocked back twenty at a sitting. Since then, Bryan played the role of post graduate supervisor, mentor, and friend to many of us. As his first post graduate fellow in 1996, I was offered totally new insights into Gastrointestinal pathology, at that time only a fledgling specialty in Sri Lanka. Many more post graduate trainees followed, including Drs Nishali Ekanayake, Renuka Gunasinghe, Manel Mangalika, Thushara Rodrigo, Isha Premathilake and Chandima De Cates nee Rajaguru. I am sure the others too enjoyed the experience of working in Oxford with Professor Warren.

I recall the long hours we spent at the microscope where he would oft remark "GI pathology requires a low power lens and a high power brain". A quote I often share now with my trainees. The number of visitors dropping by at his office were many. At times irritating, because many would also share a cup of coffee with Bryan from his $24 / 7$ coffee machine before leaving us to our work. The long hours of reporting were also punctuated by food from Headington (Bryan always knew the best take aways in the region) or a quick visit to the Social club at the John Radcliffe. His enthusiasm for GI pathology was legendary and often contagious. Many are the times he would jump up from the microscope in the midst of a reporting session with piles of slide trays yet to be attended to, and rush off to talk with his clinical colleagues - Neil Mortensen, Mike Kettlewell and Derek Jewell. He also loved to share his interesting cases with his pathology colleagues, bustling down the corridors of the cellular pathology department of the John Radcliffe and knocking on the doors of his colleagues. He established the importance of liaising closely with 
clinicians which is why he became one of the few pathologist to be a long standing member of the Association of Coloproctology. He was also determined not to become a " postal pathologist", a title his guru Professor Basil Morson coined.

The respect and care with which he approached a colorectal carcinoma specimen was amazing. He would spend hours over the specimen. Many are the occasions he would send me back into the "cut up room" to retrieve more lymph nodes. He always maintained that microscopy of colorectal carcinoma could be done by anyone but the cut up was what was of utmost importance. Professor Warren next visited Sri Lanka as examiner for MD (Histopathology). A member of the Court of Examiners of the Royal College of Surgeons of England, and a MRCP (Pathology) examiner, we in Sri Lanka were lucky to obtain his services. He gave many lectures during this period, which were considered academically stimulating and hugely entertaining. His third and last visit to Sri Lanka was as a guest of the College of Pathologists and the Gastroenterological and Digestive endoscopy society of Sri Lanka in 2000. During this visit, there were many occasions on which I drove him around the city of Colombo. This I did with much trepidation, since I was sure he noted all the shortcomings in my driving skills. A lesser known fact about Bryan, in Sri Lankan circles, is that he was a motor car enthusiast, a very active member of the Bristol car owners club and the Institute of Advanced Motorists and that he actively taught on the advanced driving courses offered by the latter. $\mathrm{He}$ was instrumental $\mathrm{n}$ the British Division of the IAP establishiing a link with the College of Pathologists of Sri Lanka. This resulted in the first International conference held by the College in 2007 based on GI pathology. Though Bryan was billed as one of the key speakers along with other illustrious speakers such as Professors Neil Shepherd and Geraint Williams, this sadly was not to be. His battle with cancer had already begun. However thanks to Bryan's efforts we have now forged a strong link with the BDAIP and have held several conferences on varying aspects of pathology. These efforts, along with numerous other contributions including his organizational skills, were duly recognized by the BDAIP in 2010, by awarding him the Cunningham Medal.

Bryan was born in Cheshire and educated in state schools in Nantwich. He was proud of the fact that he was a "grammar school boy". He studied Medicine at the University of Liverpool. He developed a great fascination for Gastroenterology which may have been partly due to his own diagnosis of Crohns disease. Though he trained in Gastroenterology, and endoscopy in particular, it was fortunate for us, that he soon turned to pathology. His early training in endoscopy contributed greatly to his remarkable ability to correlate endoscopic appearances with microscopy. His clinical acumen was duly recognized when he was elected a fellow of the Royal College of Physicians without examination in 2007. The number of papers and chapters in books published by Bryan are an indication of his commitment to research. It is even more noteworthy that all this was achieved whilst working primarily as a diagnostic pathologist. It is also heartening to note that 
there were several Sri Lankan pathologists who have been co authors in some of the papers published by Professor Warren.

Professor Bryan Fredrick Warren has undoubtedly been one of the greatest Gastrointestinal pathologists of our times and was in many ways the "Midwife of GI pathology in Sri Lanka". We in Sri Lanka join all pathologists in mourning the loss of this great man whom we admired and loved for his intelligence, his dynamism and his "joie de vivre". Above all he was a true friend of Pathology in Sri Lanka.

"Those friends thou hast and their trueness tried grapple to thy heart with hoops of steel"

Professor SJDeS Hewavisenthi 